\title{
Complex genetics of radial ray deficiencies: screening of a cohort of 54 patients
}

\author{
Sarah Vergult, MSc${ }^{1}$, A. Jeannette M. Hoogeboom, MD², Emilia K. Bijlsma, MD³, Tom Sante, MScㄹ, \\ Eva Klopocki, MSc, PhD, Bram De Wilde, MSc, MD', Marjolijn Jongmans, MD', Christian Thiel, MD', \\ Joke BGM Verheij, MD, Antonio Perez-Aytes, MD, Hilde Van Esch, MD, PhD ${ }^{7}$, Alma Kuechler, MD $^{10}$, \\ Daniela QCM Barge-Schaapveld MD ${ }^{11}$, Yves Sznajer, MD ${ }^{12}$, Geert Mortier, MD, PhD ${ }^{13}$ \\ and Björn Menten, MSc, PhD ${ }^{1}$
}

\begin{abstract}
Purpose: Radial ray deficiencies are characterized by unilateral or bilateral absence of varying portions of the radius and thumb. Both isolated and syndromic forms have been described, and although for some of the syndromes the causal gene has been identified, many patients remain without a genetic diagnosis.
\end{abstract}

Methods: In this study, a cohort of 54 patients with radial ray deficiencies was screened for genomic aberrations by molecular karyotyping.

Results: In 8 of 54 cases, an aberration was detected. Two unrelated patients inherited a 1q21.1 microduplication from a healthy parent, whereas in a third patient, a 16p13.11 microduplication was identified. Two other interesting microdeletions were detected: a 10q24.3 deletion at the split hand-foot malformation (SHFM3) locus and a $7 \mathrm{p} 22.1$ deletion including the $R A C 1$ gene.

Conclusion: The finding of these microduplications may just be coincidental or, alternatively, they may illustrate the broad phenotypic spectrum of these microduplications. Duplications in the 10q24.3 region result in split hand-foot malformations, and our observation indicates that deletions may cause radial ray defects. Finally, a candidate gene for radial ray deficiencies was detected in the $7 \mathrm{p} 22.1$ deletion. RAC1 plays an important role in the canonical Wnt pathway and conditional RAC1 knockout mice exhibit truncated-limb defects.

Genet Med 2013:15(3):195-202

Key Words array CGH; FBXW4; RAC1; radial ray deficiencies; 1q21.1 microduplication

\section{INTRODUCTION}

Radial ray deficiencies (RRDs) are characterized by unilateral or bilateral absence of varying portions of the radial ray consisting of the radius and thumb. The prevalence of these radial defects is low and varies between 1:30,000 and 1:100,000 live births. Although both isolated and syndromic forms have been described, the syndromic cases account for approximately twothirds of the patients. ${ }^{1,2}$ Known syndromes associated with radial ray defects are Holt-Oram syndrome (HOS, OMIM no. 142900), Okihiro syndrome (OMIM no. 607323), thrombocytopenia with absent radius (TAR, OMIM no. 274000), Rapadilino syndrome (OMIM no. 266280), Townes-Brocks syndrome (OMIM no. 107480), Fanconi anemia (OMIM nos. 227645, 227646, 227650, 300514, 300515, 600185, 600901, 602774, 602956, 603467, 605724, 605882, 607139, 608111, $609053,609054,609644,610355,610832,611360,613278$, and 613390), and VACTERL association (vertebral anomalies, anal atresia, cardiac abnormalities, tracheoesophageal fistula, renal anomalies, and limb anomalies, OMIM no. 192350). For some of these conditions, the causal gene has been identified.

HOS is an autosomal dominant condition associated with mutations in the transcription factor TBX5 (T-Box 5) and is characterized by upper-limb defects, congenital heart malformations, and cardiac conduction defects. When applying stringent clinical criteria, a detection rate of $74 \%$ can be achieved in patients with HOS. ${ }^{3}$ Nevertheless, not all carriers of a TBX5 mutation have the HOS phenotype, indicating phenotypic heterogeneity at this locus., ${ }^{4,5}$

The Okihiro syndrome or Duane radial ray syndrome associated with uni- or bilateral Duane anomaly and radial ray malformation has a phenotypic overlap with HOS. Mutations in the SALL4 gene (SAL-like 4), also encoding a transcription factor, are causal for this disease. ${ }^{6}$ Both TBX5 and SALL4 are involved in the same pathway, and a third gene also involved in the same processes, SALL1 (SAL-like 1), is known to cause Townes-Brocks syndrome. In addition to transcription

${ }^{1}$ Center for Medical Genetics, Ghent University, Ghent, Belgium; ${ }^{2}$ Department of Clinical Genetics, Erasmus MC, University Medical Center, Rotterdam, The Netherlands; ${ }^{3}$ Department of Clinical Genetics, Leiden University Medical Centre, Leiden, The Netherlands; ${ }^{4}$ Institute for Medical Genetics and Human Genetics, Charité Universitätsmedizin Berlin, Berlin, Germany; ${ }^{5}$ Department of Human Genetics, Radboud University Nijmegen Medical Centre, Nijmegen, The Netherlands; ${ }^{6}$ Institute of Human Genetics, University Hospital Erlangen, Erlangen, Germany; ${ }^{7}$ Department of Genetics, University Medical Center Groningen, University of Groningen, Groningen, The Netherlands; ${ }^{8}$ Dismorfología y Genética Reproductiva, Grupo de Investigación en Perinatología, Instituto de Investigación Sanitaria, Fundación Hospital La Fe, Valencia, Spain; ${ }^{9}$ Center for Human Genetics, Leuven, Belgium; ${ }^{10}$ Institut für Humangenetik, Universitätsklinikum Essen, Essen, Germany; ${ }^{11}$ Department of Clinical Genetics, Academic Medical Centre, Universiteit van Amsterdam, Amsterdam, The Netherlands; ${ }^{12}$ Center for Human Genetics, Université Catholique de Louvain, Brussels, Belgium; ${ }^{13}$ Department for Medical Genetics, University of Antwerp, Antwerp, Belgium. Correspondence: Björn Menten (Bjorn.Menten@ugent.be) 
factors, genes that are involved in DNA repair mechanisms also play a role in RRDs. Fanconi anemia, characterized by congenital malformations (including RRDs), bone marrow failure, and increased risk of malignancy, is an autosomal or X-linked recessive disorder caused by mutations in genes involved in repair mechanisms. Another layer of complexity was added in 2007 when Klopocki et al. ${ }^{7}$ reported a 1q21.1 microdeletion to be necessary but not causal for TAR syndrome (characterized by bilateral absence of the radii and thrombocytopenia), suggesting that there is a modifier at play. ${ }^{7}$ The additional causative allele was recently identified by Albers et al. ${ }^{8}$ Of 55 TAR cases examined, 53 were heterozygous carriers of the 1q21.1 microdeletion. In these patients, two low-frequency regulatory variants were identified on the other allele in the $5^{\prime} \mathrm{UTR}$ and intron 1 of the RBM8A gene. The remaining two patients were found to have the minor allele of the $5^{\prime}$ UTR single-nucleotide polymorphism in combination with either a frameshift insertion or a nonsense mutation in the RBM8A gene. This indicates that in the vast majority of cases, compound inheritance of a rare null allele (1q21.1 microdeletion (containing the RBM8A gene), frameshift mutation, or encoded premature stop codon) and one of two low-frequency noncoding single-nucleotide polymorphisms in $R B M 8 A$ cause TAR syndrome. ${ }^{8}$

Not only modifiers but also regulators such as enhancers and silencers have been suggested to play a pivotal role in limb-deficiency phenotypes. One of these enhancers is zone of polarizing activity regulating sequence, which drives normal expression of a key regulator of limb development, Shh (Sonic hedgehog) in the zone of polarizing activity. Zone of polarizing activity regulating sequence lies within intron 5 of the Lmbr1 gene $1 \mathrm{Mb}$ from the target gene, $\mathrm{Shh} .^{9}$

In this study, we selected 54 patients with a uni- or bilateral radial ray defect that did not fit any of the known syndromes or were negative for mutation screening and performed array comparative genomic hybridization (CGH) to search for genomic aberrations and new candidate genes/loci for radial ray defects.

\section{Patient selection}

\section{MATERIAL AND METHODS}

Patients with isolated and syndromal RRDs were recruited from various medical centers in Europe (Ghent, Brussels, Leuven, Antwerp, Belgium; Rotterdam, Leiden, Nijmegen, Amsterdam, Groningen, The Netherlands; Berlin, Essen, Erlangen, Germany; and Valencia, Spain). DNA samples from the parents were also collected when available. This study was approved by the ethics committee of Ghent University Hospital.

\section{Array CGH}

For all patients, the assays were performed using 180K oligonucleotide arrays (Agilent Technologies, Diegem, Belgium) as previously described.$^{10}$ For patient 8 , a $1 \mathrm{M}$ high-resolution oligonucleotide array (Agilent Technologies) was also performed. For all aberrations, the Toronto Database of Genomic Variants (http://projects.tcag.ca/variation/) was consulted.

\section{Sequencing analysis}

Sanger sequencing. The coding regions of two candidate genes for RRDs (RAC1 and FBXW4) and six conserved noncoding regions in the FBXW4 gene were sequenced using the ABI 3730XL Genetic Analyzer (Applied Biosystems, Foster City, CA). Primer sequences and PCR conditions are available upon request.

Next-generation capture sequencing. For patient 8 , a custom $1 \mathrm{M}$ capture array (Agilent Technologies) targeting the other allele of the $1.4 \mathrm{Mb}$ deletion on chromosome band 7p22.1 was made. The shotgun library of this patient was hybridized on it, followed by washing, elution, and additional amplification. All steps were performed according to the manufacturer's instructions with minor modifications; a paired-end library was made instead of a single end. The sequencing $(2 \times 45 \mathrm{bp})$ was performed on the GAIIx platform (Illumina, Eindhoven, The Netherlands). Readings were mapped to the reference genome (GRCh37) using BWA. Variant analysis was performed using an in-house tool called NXT-VAT (Next Variant Annotation Tracker; http://www.nxtvat.org).

\section{RESULTS AND DISCUSSION}

Chromosomal microarray technology has proven to be a very useful tool in the detection of aberrations in patients with intellectual disabilities and/or congenital anomalies. Its use is still expanding to other fields such as the detection of aberrations in patients with congenital malformations. ${ }^{11,12}$ To our knowledge, this is the first study using array CGH in a large cohort of patients with RRDs. In 8 of 54 patients, a genomic aberration was detected. None of these have been reported in the Toronto Database of Genomic Variants (DGV) (http://projects.tcag.ca/ variation/). Clinical and molecular data of the patients in whom an aberration was found are summarized in Table 1. Figure 1 shows the RRD in patient 8 . Clinical data of all patients are summarized in Supplementary Table S1 online.

\section{RRDs and known microduplications: a new phenotypic characteristic?}

For both patients 1 and 2, array CGH analysis revealed a 1q21.1q21.2 microduplication (Table 1 and Supplementary Figure S1a online). In both cases, the duplication was inherited from an unaffected parent.

In 2008, Mefford et al. ${ }^{13}$ and Brunetti-Pierri et al. ${ }^{14}$ reported recurrent 1q21.1 microdeletions and their reciprocal microduplications in patients with variable clinical features. The phenotypes ranged from asymptomatic to severe developmental delay with congenital anomalies. Although the microdeletion was associated with microcephaly, the reciprocal duplication was associated with macrocephaly. The majority of patients presented with mild to moderate intellectual disability and facial dysmorphism.

This 1q21.1q21.2 region is interspersed with low copy repeats, indicating that several low copy repeats could mediate genomic rearrangements. Brunetti-Pierri et al. ${ }^{14}$ suggested that there are two classes involving these distal 1q21.1 regions: 
Table 1 Clinical and molecular data of the patients in whom an aberration or substitution was detected. All genomic locations are given in GRCh37

\begin{tabular}{|c|c|c|c|c|c|c|c|}
\hline $\begin{array}{l}\text { Patient } \\
\text { no. }\end{array}$ & Sex & Radial ray defect & Other symptoms & Array CGH result & $\begin{array}{l}\text { Size aberration } \\
\text { (kb) }\end{array}$ & $\begin{array}{l}\text { Inheritance } \\
\text { pattern }\end{array}$ & $\begin{array}{l}\text { Interesting } \\
\text { gene/locus }\end{array}$ \\
\hline 1 & $\mathrm{~F}$ & $\begin{array}{l}\text { Bilateral thumb and } \\
\text { first metacarpal } \\
\text { hypoplasia }\end{array}$ & $\begin{array}{l}\text { Congenital hip } \\
\text { dysplasia, scoliosis, } \\
\text { dental anomalies, } \\
\text { and short stature }\end{array}$ & $\begin{array}{l}\text { arr } 1 q 21.1 q 21.2 \\
(146074031-147828030) \times 3\end{array}$ & 1,754 & Paternal & $\begin{array}{l}1 \mathrm{q} 21.1 \\
\text { Microduplication }\end{array}$ \\
\hline 2 & $\mathrm{~F}$ & $\begin{array}{l}\text { Bilateral radius dys- } \\
\text { plasia, Wassel type } \\
\text { I and II }\end{array}$ & $\begin{array}{l}\text { Anomalies of the } \\
\text { fifth finger }\end{array}$ & $\begin{array}{l}\text { arr } 1 q 21.1 q 21.2 \\
(146074031-147828030) \times 3\end{array}$ & 1,754 & Paternal & $\begin{array}{l}1 \mathrm{q} 21.1 \\
\text { Microduplication }\end{array}$ \\
\hline 3 & M & $\begin{array}{l}\text { Bilateral thumb } \\
\text { hypoplasia }\end{array}$ & $\begin{array}{l}\text { Bilateral syndactyly } \\
\text { of the fourth and } \\
\text { fifth finger }\end{array}$ & $\begin{array}{l}\operatorname{arr} 2 q 37.1 \\
(234136828-234229606) \times \\
1 ; \operatorname{arr} 16 p 13.11(15492307- \\
16292181) \times 3\end{array}$ & $\begin{array}{l}92.8 \\
800\end{array}$ & Not known & $\begin{array}{l}\text { 16p13.11 } \\
\text { Microduplication }\end{array}$ \\
\hline 4 & $\mathrm{~F}$ & $\begin{array}{l}\text { Bilateral radial ray } \\
\text { defects with absence } \\
\text { of right thumb and } \\
\text { radius and a dysfunc- } \\
\text { tional left thumb }\end{array}$ & $\begin{array}{l}\text { Torticollis, facial } \\
\text { dysmorphism, and } \\
\text { unilateral hearing } \\
\text { loss }\end{array}$ & $\begin{array}{l}\operatorname{arr} 8 p 23.1 \\
(6447321-6589680) \times 3\end{array}$ & 142.4 & Paternal & \\
\hline 5 & $\mathrm{~F}$ & $\begin{array}{l}\text { Bilateral radius } \\
\text { dysplasia }\end{array}$ & & $\begin{array}{l}\text { arr } 2 \text { p21 } \\
(44514880-44545015) \times 3\end{array}$ & 30.1 & Not known & \\
\hline 6 & M & $\begin{array}{l}\text { Bilateral radius } \\
\text { dysplasia }\end{array}$ & & $\begin{array}{l}\text { arr } 4 p 15.2 \\
(27060587-27620409) \times 1\end{array}$ & 559.8 & Not known & \\
\hline 7 & $\mathrm{~F}$ & $\begin{array}{l}\text { Absence of right } \\
\text { radius and thumb }\end{array}$ & $\begin{array}{l}\text { Shorter right ulna, } \\
\text { left thenar hypopla- } \\
\text { sia, and small apical } \\
\text { ventricular septal } \\
\text { defect at birth }\end{array}$ & $\begin{array}{l}\text { arr } 10 q 24.32 \\
(103352980-103433225) \times 1\end{array}$ & 80.2 & Maternal & $\begin{array}{l}\text { FBXW4/SHFM3 } \\
\text { locus }\end{array}$ \\
\hline 8 & M & $\begin{array}{l}\text { Bilateral absence } \\
\text { of radius with a } \\
\text { rudimentary thumb } \\
\text { on the left }\end{array}$ & $\begin{array}{l}\text { Microcephaly and } \\
\text { failure to thrive }\end{array}$ & $\begin{array}{l}\operatorname{arr} 7 p 22.1 \\
(5370746-6781213) \times 1\end{array}$ & $1,410.5$ & De novo & RAC1 \\
\hline 9 & M & $\begin{array}{l}\text { Bilateral radius } \\
\text { dysplasia }\end{array}$ & & Normal & & & g. $103380009 A>G$ \\
\hline
\end{tabular}

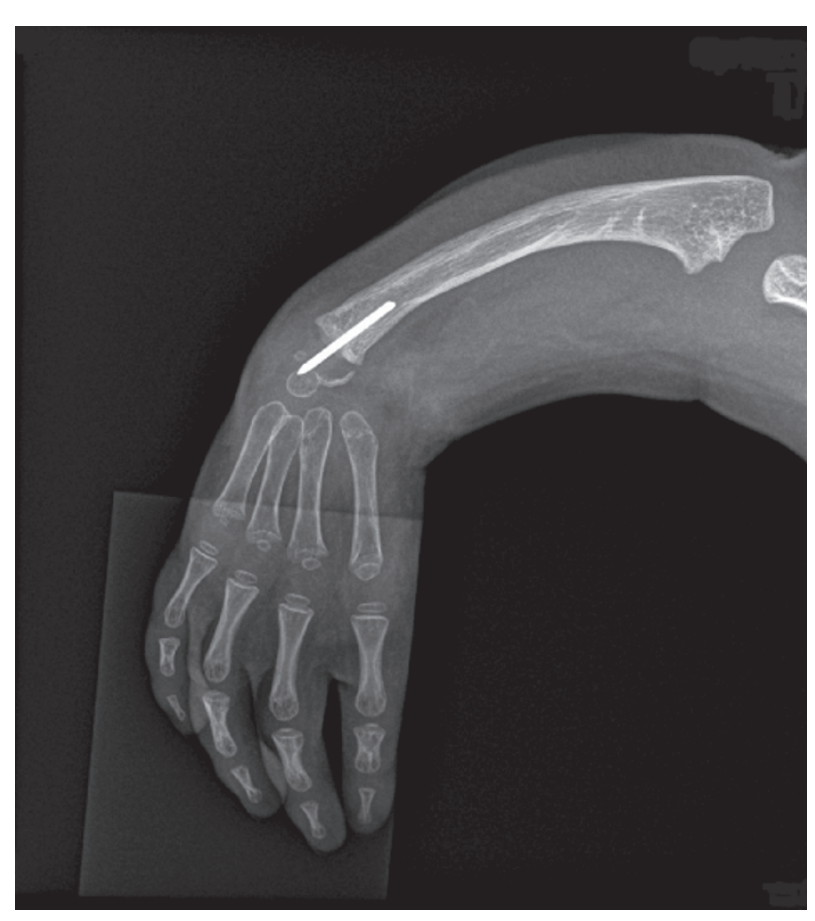

Figure 1 X-ray picture of the right arm of patient 8 in which both radius and thumb are absent. class I and class II, respectively, involving only the distal 1q21.1 region or including both the $1 \mathrm{q} 21.1$ region associated with TAR syndrome and the distal 1q21.1 region (Figure 2). No RRDs have been described in patients with class I or class II duplications. In both patients described here, there is a duplication of the distal region, not of the TAR region (Figure 2). The intellectual disability and macrocephaly reported in several patients with this duplication were not noted in the two patients described here. A ventricular septal defect was noted in patient 1 , which has also been reported in other patients with this duplication.

Patient 3 has both a $92.8 \mathrm{~kb}$ microdeletion on chromosome $2 \mathrm{q} 37.1$ and an $800 \mathrm{~kb}$ duplication on chromosome $16 \mathrm{p} 13.11$ (Table 1 and Supplementary Figure S1b,c online). Two genes reside in the 2q37.1 deletion: ATG16L1 and SAG. Neither gene has been associated with limb development. The protein encoded by ATG16L1 is part of a large protein complex that is necessary for autophagy. ${ }^{15}$ This gene has been associated with susceptibility to inflammatory bowel disease type $10 .{ }^{16,17} S A G$ encodes the $\mathrm{S}$-antigen protein, a member of the arrestin/ $\beta$ arrestin protein family and is a rod photoreceptor protein implicated in the recovery phase of light transduction. ${ }^{18,19}$ Oguchi syndrome, a rare autosomal recessive form of night blindness, has been associated with mutations in this gene..$^{20,21}$ 


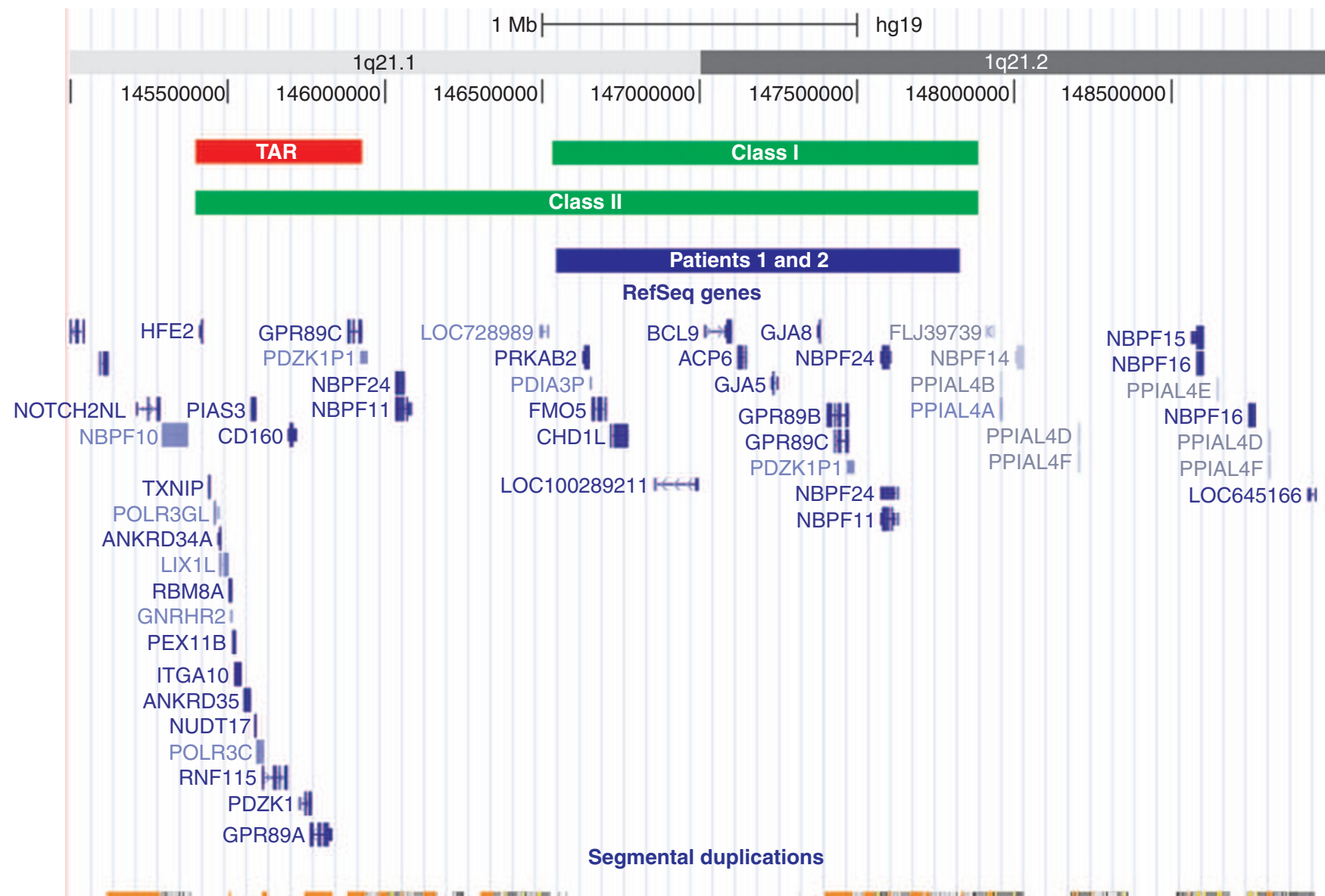

Figure 2 Overview of the 1q21.1 microduplications described in this study and those reported by Mefford et al. ${ }^{13}$ and Brunetti-Pierri et al. ${ }^{14}$ The 1q21.1 microduplications containing the distal 1q21.1q21.2 region can be divided into two classes: class I, containing only the distal region, and class II, containing both the thrombocytopenia with absent radius (TAR)-associated $1 \mathrm{q} 21.1$ region and the distal $1 \mathrm{q} 21.1 \mathrm{q} 21.2$ region. The TAR-associated $1 \mathrm{q} 21.1$ region is highlighted in red. Both the minimal regions for the class I and class II regions are highlighted in green. The minimal duplicated region in patients 1 and 2 is highlighted in blue. The blocks of segmental duplications are shown at the bottom. All coordinates are given in GRCh37.

No gastrointestinal abnormalities or night blindness have been observed in patient 3 .

Duplications of the $16 \mathrm{p} 13.11$ region have been suggested to be causally associated with intellectual disability, behavioral abnormalities such as aggressive behavior, congenital heart defects, and skeletal manifestations such as hypermobility and craniosynostosis. ${ }^{22}$ Numerous low copy repeats, also known as segmental duplications, are contained in the 16p13.11 locus (Figure 3). Ingason et al. ${ }^{23}$ subdivided the locus into three single-copy sequences (I, II, and III) interspersed with stretches of segmental duplications. These single-copy regions are shown as black bars in Figure 3. The reported 16p13.11 duplications are all contained within this locus, with the most common breakpoints in the low copy repeat clusters distal to interval I and proximal to interval II. In patient 3 described here, interval II is duplicated. As parental DNA was unavailable, the de novo status of the duplication could not be checked.

It is unclear whether duplications of $16 \mathrm{p} 13.11$ are causal or benign variants. ${ }^{24}$ Recently, Cooper et al. ${ }^{25}$ compared copy- number variants in 15,767 children with intellectual disability and various congenital defects with 8,329 adult controls. No significant enrichment was observed for the 16p13.11 duplication in patients as compared with controls. Because herein we report a small series of patients, and no RRDs have been reported in patients with the 16p13.11 duplication, the detection of a 16p13.11 duplication in our cohort is likely a coincidental finding. Although the 1q21.1 microduplication is significantly enriched in patients vs. controls, ${ }^{13,25}$ our cohort is too small to confirm RRDs as a new characteristic of this syndrome. To investigate whether these aberrations play a role in RRD or are just coincidental findings, many additional individuals with RRDs need to be analyzed.

\section{FBXW4 as a candidate locus}

In patient 7, a small deletion of $80.2 \mathrm{~kb}$ was detected on chromosome band 10q24.3 using array CGH. Of note, this deletion contains a single gene, FBXW4 (Figure 4a) (F-Box WD repeat domain containing 4). FBXW4 belongs to the F-box/ 


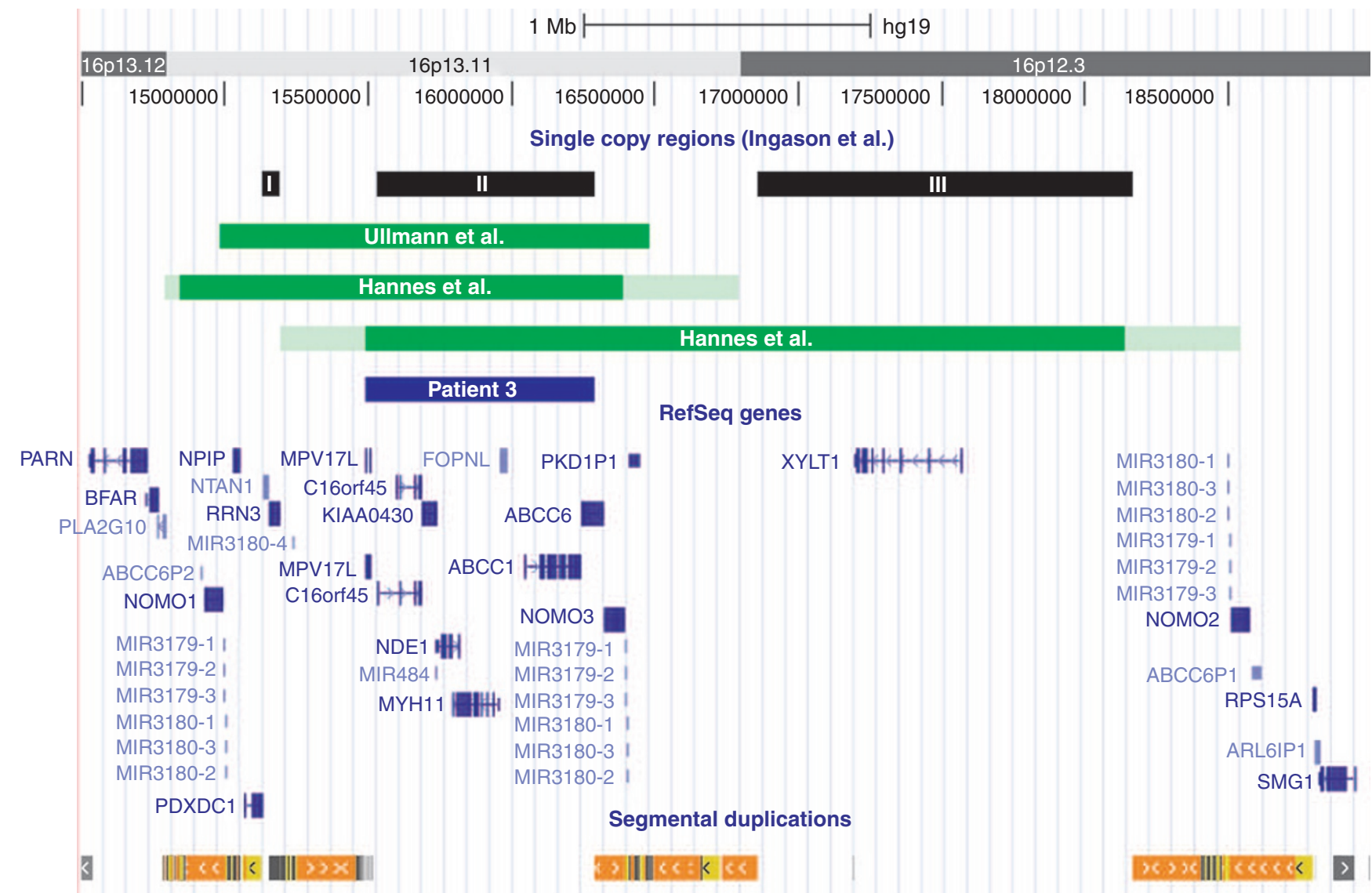

Figure 3 Overview of the $16 \mathrm{p} 13.11$ microduplication described in this study and those reported by Ullmann et al. ${ }^{22}$ and Hannes et al. ${ }^{24}$ Both the duplications reported by Ullmann et al..$^{22}$ and Hannes et al. ${ }^{24}$ are highlighted in green. The minimal and maximal duplicated regions reported by Hannes et al. ${ }^{24}$ are highlighted in dark and light green, respectively. The single-sequence intervals referred to as intervals I, II, and III by Ingason et al. ${ }^{23}$ are highlighted in black at the top. The minimal duplicated region in patient 3 is shown in blue. The flanking segmental duplications are shown at the bottom. All coordinates are given in GRCh37.

WD-40 gene family, which is involved in ubiquitin-mediated degradation.

Molecular analysis of the parents revealed that the deletion was inherited from the unaffected mother. Nevertheless, this gene was of high interest because insertions in the ortholog dactylin gene give rise to dactylaplasia in mice. In humans, duplications of this 10q24 region are associated with split hand-foot malformation (SHFM3) with a high phenotypic variability and reduced penetrance. ${ }^{26}$ How these duplications cause SHFM3 is still not known. Because several genes in the vicinity, such as FGF8, have a role in limb development, it has been suggested that these duplications could disrupt the interaction between cis-regulatory elements and their target genes, resulting in the SHFM phenotype. ${ }^{27}$

Regulatory elements at the FBXW4 locus. The deletion in patient 7 was inherited from the mother. Reduced penetrance, as also seen with the 10q24.3 duplications, may be possible in this case. In view of this, one can postulate that the 10q24.3 deletion gives rise to RRDs by deletion of one or more specific regulatory regions. To test this hypothesis, six conserved noncoding elements ( $\geq 350 \mathrm{bp}$ and sharing $\geq 90 \%$ identity with the mouse and/or $\geq 100 \mathrm{bp}$ and sharing $\geq 70 \%$ identity with the frog and/or zebrafish) were selected in the deleted region on 10q24.3 (Figure $4 \mathbf{b}$ ) based on literature review and on the use of the ECR (http:// ecrbrowser.dcode.org/), Ancora (http://ancora.genereg. net/), and UCSC Genome Browser (http://genome.ucsc. edu/) and were sequenced in the entire patient cohort. In patient 9, an A to G transition (Supplementary Figure S2 online) on genomic position 103380009 (GRCh 37) was detected that was neither a single-nucleotide polymorphism nor present in a control cohort of 96 samples matched to the ethnicity of patient 9 or in the 1000 Genomes Project data (http://browser.1000genomes.org). For patient 9, no causal aberrations were detected using array CGH (Table 1). Unfortunately parental DNA was unavailable. This $A \rightarrow G$ substitution could account for the RRDs seen in this patient, but functional studies need to be performed to further investigate this. Sequence analysis of the exons of FBXW4 did not reveal causal mutations in the patient with the heterozygous FBXW4 deletion or in any other patient of our cohort. 
a

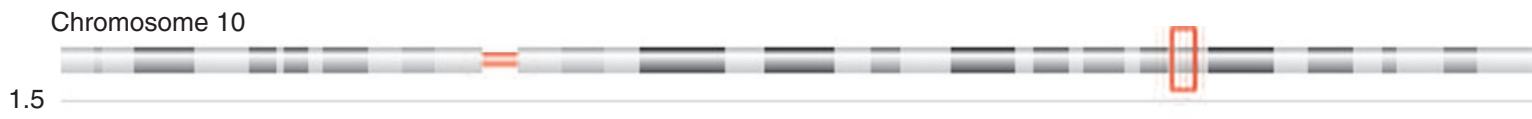

1

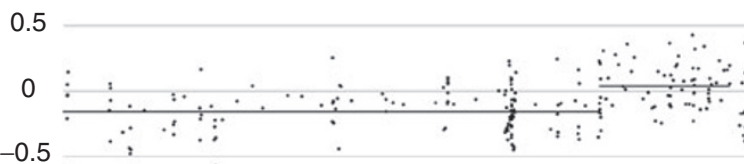

$-1$

$-1.5$

$102.35 \mathrm{Mb}$

103.35 Mb

104.35

\begin{tabular}{|c|c|c|}
\hline Segdups & II & 1 \\
\hline
\end{tabular}

FBXW4

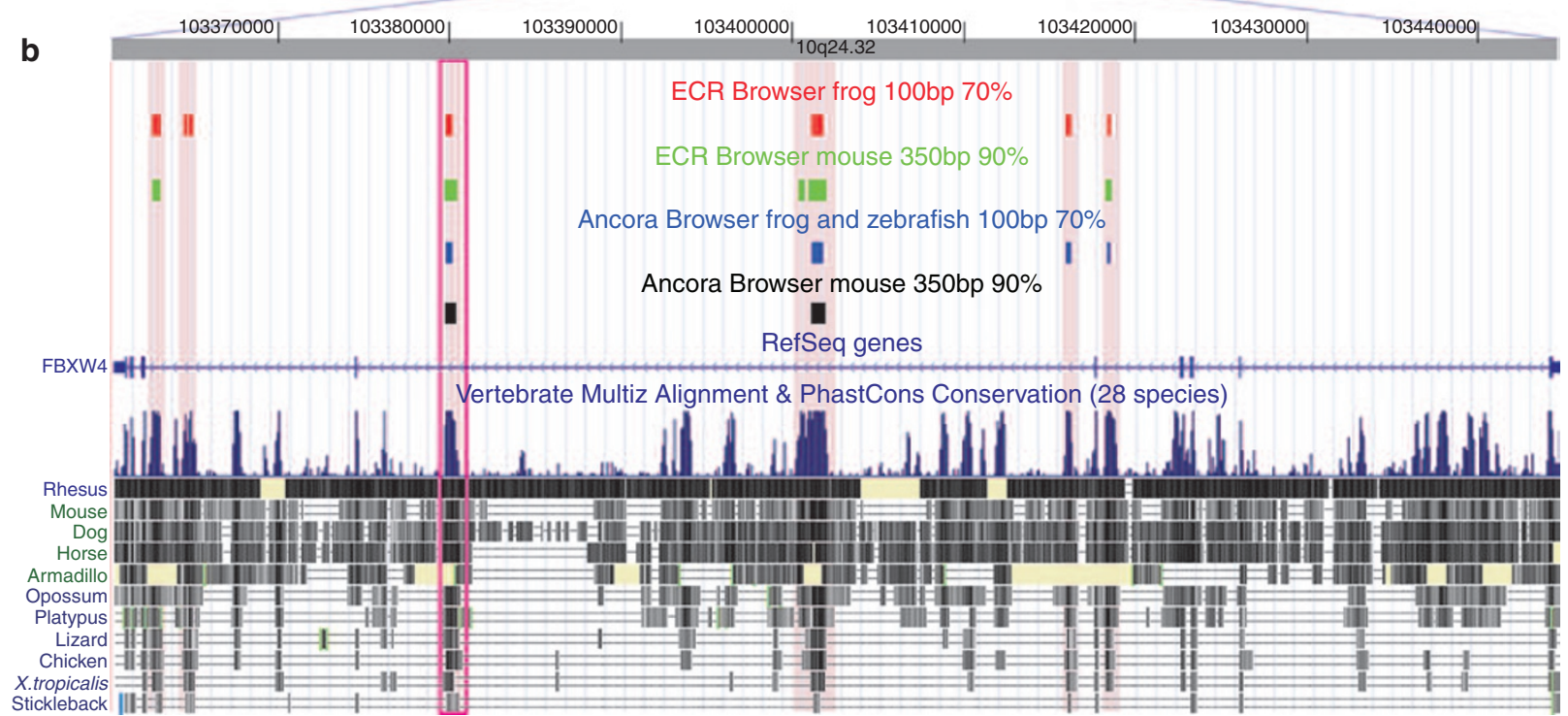

C

Chromosome 7

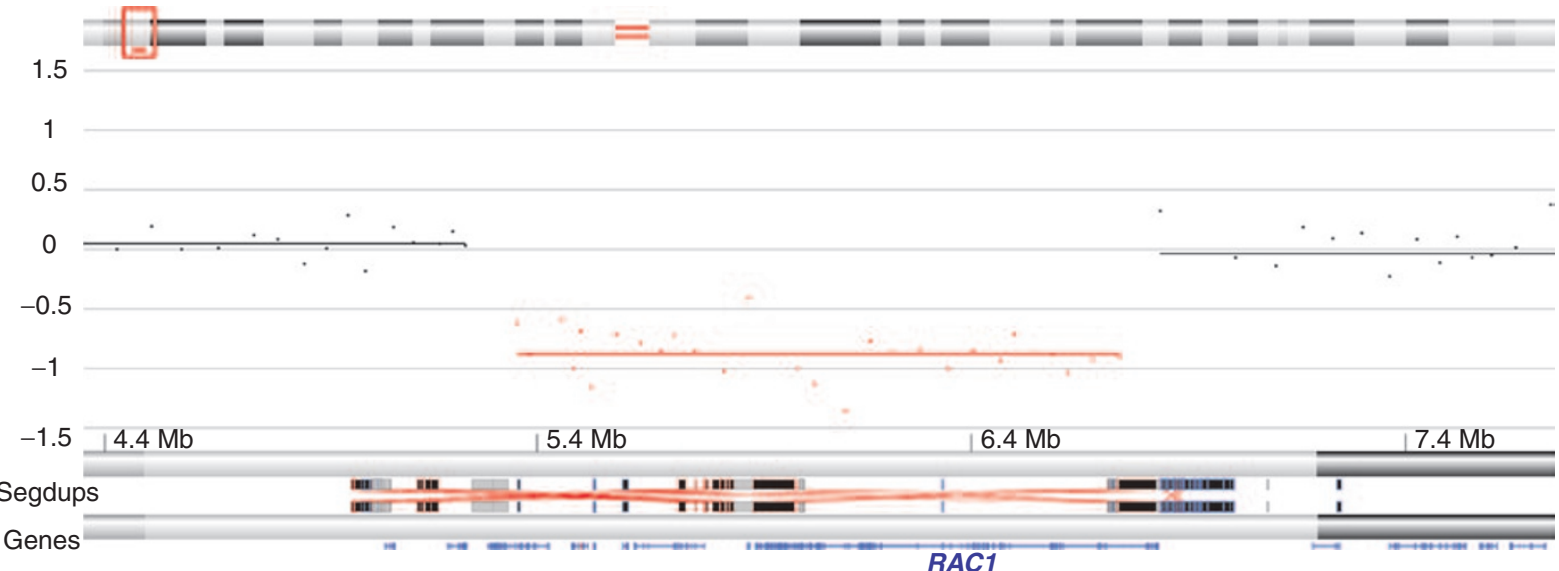

Figure 4 Deletion identified in patient 7 and 8. (a) 10q24.3 deletion in patient 7 that comprises only one gene, FBXW4. The region associated with SHFM3 (green) and FGF8 (red), a gene known to play a role in limb development, are highlighted at the bottom. (b) Overview of FBXW4 and the six selected conserved noncoding elements (in red). The conserved element containing the substitution (Supplementary Figure S2 online) is highlighted by a red box. (c) $7 \mathrm{p} 22.1$ deletion in patient 8 . The candidate gene, RAC1, is highlighted in blue. The coordinates of the aberrations are given in GRCh37. Segmental duplications (Segdups) and genes in or near the aberrations are marked at the bottom of each figure. 


\section{RAC1 as a candidate gene}

Array $\mathrm{CGH}$ analysis revealed a de novo $1.4 \mathrm{Mb}$ deletion in patient 8 on chromosome band 7p22.1. In this deletion, 22 RefSeq genes reside, in addition to 1 micro RNA and 3 long intergenic noncoding RNAs (Table 1 and Figure 4c).

Of the genes residing in the $7 \mathrm{p} 22.1$ deletion, $R A C 1$ is of particular interest. This gene encodes a member of the Rho GTPase family and plays an important role in several pathways. In 2008 , Wu et al. ${ }^{28}$ reported that $R A C 1$ influences the canonical Wnt signaling pathway by recruiting $\beta$-catenin to the nucleus. Signaling of $\beta$-catenin is known to play an essential role in limb development. Of note, mice subjected to conditional knockout of RAC1 (limb bud ectoderm) exhibit truncated forelimbs and hind limbs that resemble those observed in $\beta$-catenin knockout mice. Recently, it was also shown that conditional deletion of RAC1 in the mouse limb bud mesenchyme leads to skeletal deformities, including abnormal fusion of the skull, developmental limb defects, and syndactyly. ${ }^{29}$ Furthermore, overexpression of ARHGAP31, a negative regulator of CDC42 and RAC1, is associated with cutis aplasia and upper- and/or lower-limb defects of significant variability and reduced penetrance. ${ }^{30}$ All of these reports indicate a crucial role for RAC1 in limb development.

To exclude the unmasking of a recessive allele by the $7 \mathrm{p} 22.1$ deletion, capture sequencing was performed on patient 8 . The average coverage was $77 \times$. In addition to the coding sequences in the 7 p22.1 region, the four noncoding RNA genes in that region were analyzed. No mutations were detected on the other allele.

For this patient, the de novo 7p22.1 deletion and in particular the deletion of $R A C 1$ appears to cause the radial ray defects. Of note, in 2009 Chen et al. ${ }^{31}$ reported that conditional knockout of RAC1 in the forebrain results in microcephaly, which is also present in patient 8 .

The Decipher database (https://decipher.sanger.ac.uk/) contains three patients with a de novo deletion of $R A C 1$, in patients 998, 250734, and 256546. Microcephaly is reported as one of the phenotypic features for the first two patients, indicating $R A C 1$ is the most likely candidate gene for the microcephaly seen in these patients. As patient 8 is still very young, other features that may be caused by haploinsufficiency of (one of) the other genes, may become apparent during development.

Because RAC1 is the most likely candidate gene for the RRDs, sequence analysis of this gene was performed in our entire patient cohort. No other causal mutations were detected. More patients and/or further research are needed to unravel the role of RAC1 in limb development/RRDs as well as in microcephaly.

\section{Other aberrations}

In three other patients, an aberration not present in the DGV was detected. A small duplication of $142.4 \mathrm{~kb}$ on chromosome band 8p23.1 was detected in patient 4, a $30.1 \mathrm{~kb}$ duplication on chromosome band $2 \mathrm{p} 21$ was detected in patient 5 , and a $559.8 \mathrm{~kb}$ microdeletion on chromosome band $4 \mathrm{p} 15.2$ was detected in patient 6 (Table 1 and Supplementary Figure S1d-f online). The 8p23.1 duplication was inherited from the unaffected father. Unfortunately, parental DNA from the latter two patients was not available.

Two genes, MCPH1 and AGPAT5, lie in the 8p23.1 duplicated region from patient 4 . Neither has a known function in limb development. The 2 p21 deletion in patient 5 was also detected in a patient without RRDs (data not shown). The third aberration, the $4 \mathrm{p} 15.2$ deletion in patient 6 , contains no coding genes. Analysis of the coding genes within a proximity of $1 \mathrm{Mb}$ of the deletion did not reveal any gene having a clear role in limb development. Of note, three long intergenic noncoding RNAs reside in the deletion. Not much is known about the functions of these long intergenic noncoding RNAs. Recently, it has been shown that long intergenic noncoding RNAs are important in the regulation of gene expression and during developmental stages. ${ }^{32,33}$ For all three patients, the clinical significance of the duplication/deletion remains unknown. This clearly highlights the need for more patients, and apart from this, parental analysis still remains one of the first steps in the evaluation of a copy-number variant of unknown significance. ${ }^{10}$

\section{Conclusion}

This is the first study to use array CGH in a cohort of patients with RRDs. We identified eight microdeletions and duplications in a series of 54 patients. The finding of distal 1q21.1 microduplications in two unrelated patients and a $16 \mathrm{p} 13.11$ microduplication in another patient is interesting because limb defects have not been reported in patients with these microduplications. These may just be coincidental findings or, alternatively, they may illustrate the broad phenotypic spectrum of these microduplications. The observation of a 7 p22.1 deletion in patient 8 is also an interesting finding, especially because the $R A C 1$ gene, which resides in the deleted region, is a good candidate gene for the radial ray abnormalities in this patient. Mouse models with RAC1 knockout exhibit limb defects. It is not yet clear how the heterozygous deletion of RAC1 in patient 8 contributes to the phenotype. The possibility of unmasking a recessive allele was excluded. The analysis of $R A C 1$ in the other patients did not reveal intragenic mutations. Finally, the deletion on 10q24, encompassing the FBXW4 gene, was further investigated. Duplications in this region result in SHFM malformation, and our observation indicates that deletions may cause radial ray defects. The question of whether the deletion of the FBXW4 gene itself or the presence of mutations in the flanking conserved noncoding regions are responsible for the limb defect remains open.

\section{ACKNOWLEDGMENTS}

S.V. and B.D.W. are supported by a PhD fellowship of the Research Foundation-Flanders (FWO). Geert Mortier was senior clinical investigator at the FWO until 2010. This work was supported by grant SBO60848 from the Institute for the Promotion of Innovation by Science and Technology in Flanders (IWT) 
and a Methusalem grant of the Flemish government. This article presents research results of the Belgian program of Interuniversity Poles of Attraction initiated by the Belgian State, Prime Minister's Office, Science Policy Programming (IUAP). The authors are indebted to all patients, their families, and the clinicians involved for their cooperation. We thank Lies Vantomme, Shalina Baute, and Xenia Leroy for expert technical assistance.

\section{SUPPLEMENTARY MATERIAL}

Supplementary material is linked to the online version of the paper at http://www.nature.com/gim

\section{DISCLOSURE}

The authors declare no conflict of interest.

\section{REFERENCES}

1. Goldfarb CA, Wall L, Manske PR. Radial longitudinal deficiency: the incidence of associated medical and musculoskeletal conditions. J Hand Surg Am 2006;31:1176-1182.

2. James MA, Green HD, McCarroll HR Jr, Manske PR. The association of radial deficiency with thumb hypoplasia. J Bone Joint Surg Am 2004;86-A: 2196-2205.

3. McDermott DA, Bressan MC, He J, et al. TBX5 genetic testing validates strict clinical criteria for Holt-Oram syndrome. Pediatr Res 2005;58:981-986.

4. Basson CT, Bachinsky DR, Lin RC, et al. Mutations in human TBX5 [corrected] cause limb and cardiac malformation in Holt-Oram syndrome. Nat Genet 1997; 15:30-35.

5. Li QY, Newbury-Ecob RA, Terrett JA, et al. Holt-Oram syndrome is caused by mutations in TBX5, a member of the Brachyury (T) gene family. Nat Genet 1997;15:21-29.

6. Kohlhase J, Heinrich M, Schubert L, et al. Okihiro syndrome is caused by SALL4 mutations. Hum Mol Genet 2002;11:2979-2987.

7. Klopocki E, Schulze H, Strauss G, et al. Complex inheritance pattern resembling autosomal recessive inheritance involving a microdeletion in thrombocytopeniaabsent radius syndrome. Am J Hum Genet 2007;80:232-240.

8. Albers CA, Paul DS, Schulze H, et al. Compound inheritance of a low-frequency regulatory SNP and a rare null mutation in exon-junction complex subunit RBM8A causes TAR syndrome. Nature Genet 2012;44:435-439, S1-S2.

9. Lettice LA, Horikoshi T, Heaney SJ, et al. Disruption of a long-range cisacting regulator for Shh causes preaxial polydactyly. Proc Natl Acad Sci USA 2002;99:7548-7553.

10. Buysse K, Delle Chiaie B, Van Coster R, et al. Challenges for CNV interpretation in clinical molecular karyotyping: lessons learned from a 1001 sample experience. Eur J Med Genet 2009;52:398-403.

11. Wat MJ, Veenma D, Hogue J, et al. Genomic alterations that contribute to the development of isolated and non-isolated congenital diaphragmatic hernia. J Med Genet 2011;48:299-307.

12. Balikova I, de Ravel T, Ayuso C, et al. High frequency of submicroscopic chromosomal deletions in patients with idiopathic congenital eye malformations. Am J Ophthalmol 2011;151:1087-1094, e1045.

13. Mefford HC, Sharp AJ, Baker C, et al. Recurrent rearrangements of chromosome 1q21.1 and variable pediatric phenotypes. N Engl J Med 2008;359: 1685-1699.
14. Brunetti-Pierri N, Berg JS, Scaglia F, et al. Recurrent reciprocal 1q21.1 deletions and duplications associated with microcephaly or macrocephaly and developmental and behavioral abnormalities. Nat Genet 2008;40:1466-1471.

15. Mizushima N, Kuma A, Kobayashi Y, et al. Mouse Apg16L, a novel WD-repeat protein, targets to the autophagic isolation membrane with the Apg12-Apg5 conjugate. J Cell Sci 2003;116(Pt 9):1679-1688.

16. Hampe J, Franke A, Rosenstiel P, et al. A genome-wide association scan of nonsynonymous SNPs identifies a susceptibility variant for Crohn disease in ATG16L1. Nat Genet 2007;39:207-211.

17. Franke A, Fischer A, Nothnagel $M$, et al. Genome-wide association analysis in sarcoidosis and Crohn's disease unravels a common susceptibility locus on 10p12.2. Gastroenterology 2008;135:1207-1215.

18. Ngo JT, Klisak I, Sparkes RS, et al. Assignment of the S-antigen gene (SAG) to human chromosome 2q24-q37. Genomics 1990;7:84-87.

19. Yamaki K, Tsuda M, Kikuchi T, Chen KH, Huang KP, Shinohara T. Structural organization of the human S-antigen gene. CDNA, amino acid, intron, exon, promoter, in vitro transcription, retina, and pineal gland. J Biol Chem 1990;265:20757-20762.

20. Fuchs S, Nakazawa M, Maw M, Tamai M, Oguchi Y, Gal A. A homozygous 1-base pair deletion in the arrestin gene is a frequent cause of Oguchi disease in Japanese. Nat Genet 1995;10:360-362.

21. Nakazawa $M$, Wada $Y$, Tamai $M$. Arrestin gene mutations in autosomal recessive retinitis pigmentosa. Arch Ophthalmol 1998;116:498-501.

22. Ullmann R, Turner G, Kirchhoff M, et al. Array CGH identifies reciprocal 16p13.1 duplications and deletions that predispose to autism and/or mental retardation. Hum Mutat 2007;28:674-682.

23. Ingason A, Rujescu D, Cichon S, et al.; GROUP Investigators. Copy number variations of chromosome 16p13.1 region associated with schizophrenia. Mol Psychiatry 2011;16:17-25.

24. Hannes FD, Sharp AJ, Mefford HC, et al. Recurrent reciprocal deletions and duplications of 16p13.11: the deletion is a risk factor for MR/MCA while the duplication may be a rare benign variant. J Med Genet 2009;46:223-232.

25. Cooper GM, Coe BP, Girirajan S, et al. A copy number variation morbidity map of developmental delay. Nat Genet 2011;43:838-846.

26. Dimitrov $\mathrm{BI}$, de Ravel $\mathrm{T}$, Van Driessche J, et al. Distal limb deficiencies, micrognathia syndrome, and syndromic forms of split hand foot malformation (SHFM) are caused by chromosome 10q genomic rearrangements. J Med Genet 2010;47:103-111.

27. Friedli M, Nikolaev S, Lyle R, et al. Characterization of mouse Dactylaplasia mutations: a model for human ectrodactyly SHFM3. Mamm Genome 2008; 19:272-278.

28. Wu X, Tu X, Joeng KS, Hilton MJ, Williams DA, Long F. Rac1 activation controls nuclear localization of beta-catenin during canonical Wnt signaling. Cell 2008;133:340-353.

29. Suzuki D, Yamada A, Amano T, et al. Essential mesenchymal role of small GTPase Rac1 in interdigital programmed cell death during limb development. Dev Biol 2009;335:396-406

30. Southgate L, Machado RD, Snape KM, et al. Gain-of-function mutations of ARHGAP31, a Cdc42/Rac1 GTPase regulator, cause syndromic cutis aplasia and limb anomalies. Am J Hum Genet 2011;88:574-585.

31. Chen L, Melendez J, Campbell K, Kuan CY, Zheng Y. Rac1 deficiency in the forebrain results in neural progenitor reduction and microcephaly. Dev Biol 2009:325:162-170

32. Wang KC, Yang YW, Liu B, et al. A long noncoding RNA maintains active chromatin to coordinate homeotic gene expression. Nature 2011;472: 120-124.

33. Pauli A, Valen E, Lin MF, et al. Systematic identification of long non-coding RNAs expressed during zebrafish embryogenesis. Genome Res 2012;22:577-591. 